\title{
Application of molecular techniques in the study of Staphylococaus aureus clonal evolution - A Review
}

\author{
Adriana Marcos Vivoni, Beatriz Meurer Moreira+
}

\author{
Instituto de Microbiologia Professor Paulo de Góes, CCS, Bloco I, Universidade Federal do Rio de Janeiro, 21941-590 \\ Rio de Janeiro RJ, Brasil
}

\begin{abstract}
Staphylococcus aureus is an important agent of healthcare-associated and community-acquired infections. A major characteristic of this microorganism is the ability to develop resistance to antimicrobial agents. Several molecular techniques have been applied for the characterization of S. aureus in epidemiological studies. In the present review, we discuss the application of molecular techniques for typing $\mathrm{S}$. aureus strains and describe the nomenclature and evolution of epidemic clones of this important pathogen.
\end{abstract}

Key words: Staphylococcus aureus - pulsed field gel electrophoresis - multilocus sequence typing - staphylococcal cassette chromosome mec typing - epidemiology

During the last decade, Staphylococcus aureus was recognized as the most frequent agent of bloodstream and skin infections in Latin American hospitals (Diekema et al. 2001). Acquisition of resistance to several antimicrobial agents has been a major problem for the treatment of infections by this pathogen in the hospital and community settings. Resistance to $\beta$-lactam agents that resist hydrolysis of penicillinase, such as methicillin and oxacillin, is named "methicillin resistance" and is considered of great importance since oxacillin is the drug of choice for the treatment of $S$. aureus infections (Paradisi et al. 2001). The first cases of methicillin-resistant $S$. aureus (MRSA) were reported in the early 1960s, a few years after the introduction of methicillin in therapeutics (Jevons 1961). MRSA isolates produce a new penicillinbinding protein (PBP), called PBP2a or PBP2', with low affinity for $\beta$-lactam drugs, encoded by the $m e c A$ gene (Chambers 1997). MRSA is currently the most commonly identified antibiotic-resistant pathogen in US hospitals (NNIS 2004).

Molecular typing techniques are widly applied in studies of $S$. aureus epidemiology, especially MRSA, with the aim of distinguishing isolates that are epidemiologically related from those unrelated. S. aureus outbreaks in hospitals are frequently considered as short duration events of localized epidemiology and, in these situations, most of the molecular typing methods are able to distinguish the isolates that belong to the outbreak (Shopsin \& Kreiswirth 2001). However, the study of isolates that do not share a temporal or geographic origin, to define ancestors and lineages, is a major challenge. To date, several techniques allowed for the investigation and charac-

Financial suport: CNPq, Capes, Faperj, the Fogarty International Program in Research and Training in Emerging Infectious Diseases (TW006563) NIH

+Corresponding author. Email: bmeurera@alternex.com.br

Received 8 July 2005

Accepted 14 September 2005 terization of MRSA epidemic clones, but there are few data available about methicillin-susceptible $S$. aureus (MSSA). However, MSSA still causes about 50\% of the healthcare-associated infections and almost all the staphylococcal community-acquired infections.

Molecular typing techniques employed in the study of S. aureus epidemiology

One of the first molecular techniques applied to study S. aureus epidemiology was the determination of the electrophoretic migration profile of plasmids in agarose gels. After the polymerase chain reaction (PCR) technique became available, several methods were developed and have been applied for S. aureus typing. PCR technology allows the evaluation of the structural organization of resistance determinants, such as the $m e c A$ gene, in isolates of different origins (Lim et al. 2002). In addition, some sequences can be used as targets for PCR-typing, such as the Tn916-Shine-Dalgarno (Netto dos Santos et al. 2001). A different approach is the repetitive extragenic palindromic-PCR (Rep-PCR), using primers that target repetitive extragenic palindromic DNA regions. This method has been used for typing MRSA (Del Vecchio et al. 1995) as well as MSSA (Netto dos Santos et al. 2001) isolates. Moreover, primers can target random DNA sites, such as in random amplified polymorphic DNA (RAPD) and amplified fragment length polymorphism (AFLP) techniques (Saulnier et al. 1993, Grundmann et al. 2002). However, to date, no appropriate criteria have been developed to interpret data obtained with these techniques.

The first studies on the global molecular epidemiology of $S$. aureus

A major progress in the understanding of the global epidemiology of S. aureus occurred after the development of multilocus enzyme electrophoresis (MLEE), a technique to analyze the electrophoretic mobility of housekeeping enzymes (Boerlin 1997). Interesting data were reported in 1992 by Musser and Kapur by the analysis of 254 MRSA isolates obtained in nine different countries of four continents, between 1961 and 1992. The authors reported that the mecA gene was inserted in isolates of 
different $S$. aureus lineages, suggesting that the acquisition of mecA was a horizontal transmission event that occurred several times in MSSA giving origin to different MRSA lineages (Musser \& Kapur 1992). However, diverging results were published by Kreiswirth et al. in 1993. In this study, 472 MRSA isolates recovered from countries of four continents were analyzed by DNA restriction with $\mathrm{Cla}$ I followed by hybridization with probes for $m e c A$ and Tn554. All isolates could be divided into a limited number of mecA hybridization patterns, suggesting that $m e c A$ was most likely acquired by $S$. aureus only once, and all MRSA clones were descendents of this prototype strain. This hypothesis was accepted until the middle 1990s.

\section{Evolution of typing techniques and the charac- terization of MRSA epidemic clones}

The study of S. aureus epidemiology achieved a major advance with the application of pulsed field gel electrophoresis (PFGE). In this technique, bacterial DNA is immobilized into agarose plugs where endonuclease digestion is carried out. Electrophoresis is then run under an electric field that changes in pre-determined intervals, allowing for the separation of DNA fragments ranging from $10 \mathrm{~Kb}$ to $800 \mathrm{~Kb}$ (Olive \& Bean 1999), while the conventional electrophoresis allows the separation of fragments ranging from $500 \mathrm{pb}$ to $20 \mathrm{~Kb}$. In 1995, Tenover et al. proposed a protocol for the interpretation of results obtained by PFGE. The interpretation system was based on results obtained by the application of PFGE to groups of isolates involved in well-characterized $S$. aureus nosocomial outbreaks. Accordingly, at first, the isolates presenting the most common pattern are defined as the outbreak strain. Then, the number of fragment differences in the electrophoretic patterns of all other tested isolates are compared to the outbreak strain, and the analysis is carried out, as follows: if no differences are found, isolates are considered part of the outbreak; with one to three differences (one genetic event), isolates are considered probably related to the outbreak strain; with four to six differences, isolates are considered possibly related to the outbreak strain; and finally, with more than six differences, isolates are considered as unrelated to the outbreak strain. Tenover and collaborator's criteria proved to be very useful, making PFGE suitable for epidemiological studies involving isolates from a restricted area, recovered during a three-month period, or even more, and have been successfully applied in several studies (Hilton et al. 2002, Montesinos et al. 2002, Wei \& Chiou 2002).

Although interpretation criteria for PFGE had been proposed for the analysis of isolates recovered in a period of up to three months, the technique has been effectively applied in several studies of global epidemiology. The combination of PFGE and the study of ClaI::mecA and ClaI::Tn554 polymorphism patterns led to the characterization of five major MRSA clones or lineages described bellow. These clones were named Iberian, Brazilian, Hungarian, New York/Japan and Pediatric, reflecting the geographic region where they were first identified or indicating a unique epidemiological characteristic.
The combination of the polymorphisms ClaI::mecA type I and ClaI::Tn554 type E (I::E) characterizes the Iberian Clone (IC). This MRSA clone was first described in Spain, 1989 (Dominguez et al. 1994) and later on, in Portugal (Ferrari et al. 2002), Italy and United Kingdom (Mato et al. 1998), Germany (Witte et al. 1994), Belgium, Switzerland, France (Deplano et al. 2000), Poland (Leski et al. 1998), Check Republic (Melter et al. 2003), and United States (Roberts et al. 1998a).

The Hungarian Clone (HC) is characterized by the combination III::B. It was first described as extensively disseminated in Hungarian hospitals (Sanches et al. 1998), and later on, reported in hospitals in Thailand (Crisóstomo et al. 2001).

The New York/Japan Clone is characterized by the combination I::A and was first identified as the predominant clone in New York (Roberts et al. 1998b), New Jersey, Pennsylvania, and Connecticut hospitals in US (Roberts et al. 2000). It was also described in a hospital in Tokyo (Aries et al. 2000).

The Pediatric Clone is characterized by the combination II::NH and was first described in 1992, in a pediatric hospital in Portugal (Sa-Leao et al. 1999). It was also reported in Poland (Leski et al. 1998), US (Roberts et al. 1998b), Argentina (Corso et al. 1998), Colombia (Gomes et al. 2001), and Brazil (Nunes de Melo et al. 2004).

The Brazilian Clone (BC) was first described by Teixeira et al. (1995) as the combination III::B. However, Oliveira et al. (2002) described the same clone as XI::B and the HC as III::B. Nevertheless, in 1994, Sader et al. (1994) had already reported the occurrence of an endemic MRSA clone in eight hospitals in São Paulo city. This was named SP Clone and was probably the first report of the BC. However, differences between the PFGE protocol used by Sader et al. and the other authors mentioned above makes the comparison of their results impossible. Later on, the BC was reported in Portugal (de Sousa et al. 1998), Argentina, Uruguay, Chile (Aires et al. 2001), and the Check Republic (Melter et al. 2003).

According to Oliveira al. (2002), the dissemination of MRSA clones in some wide geographic areas probably reflects their increased ability to cause infections, persist and disseminate from one region to another, including different continents.

Although PFGE is an appropriate technique to study outbreaks, it is not sufficient for long-term studies or for studies of global epidemiology. In addition to the limitations of the interpretation criteria related to short time periods and restricted geographic areas, PFGE presents reproducibility problems. Different results are obtained when the technique is performed in different laboratories, even when standardized conditions are used (van Belkum et al. 1998, Olive \& Bean 1999).

In 2000, Enright et al. described, for the first time, the application of multilocus sequence typing (MLST) for the characterization of MRSA and MSSA isolates. MLST is a genotypic version of MLEE where isolates are typed by sequencing variable regions of housekeeping genes (Table I). Each new sequence is a new allele, and the combination of seven alleles forms the allelic profile or sequence type (ST). The results of MLST have been used to build a 
database that allows comparisons among $S$. aureus isolates from all over the world. This database can be accessed in the website http://www.mlst.net. A limitation of MLST is, however, the need of DNA sequencing, which is restricted to few institutions.

Right after MLST was described for S. aureus typing, a new approach was proposed to study MRSA: the staphylococcal cassette chromosome mec (SCCmec) typing. The genetic element SCCmec, described by Katayama et al. (2000), is responsible for the mobilization of the mecA gene and harbors $c c r A, c c r B$ or $c c r C$ genes, which encode chromosome recombinases, and the mec complex. The proteins encoded by the $c c r$ genes drive the excision and integration of the cassette in a specific site of the $S$. aureus chromosome (attBscc) located close to the origin of replication. The allotypes 1,2,3, and 4 were described for $c c r A$ and $c c r B$, whereas only allotype 5 was described for $\operatorname{ccr} C$ (Ma 2004). In addition to the mecA gene, the mec complex carries other genetic elements. Three classes of the mec complex, presenting distinct structures, were described for $S$. aureus: class A (mecI-mecR1-mecA-

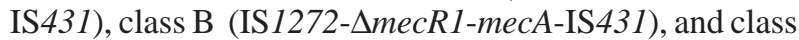
C2 (IS431-mecA- $\Delta m e c R 1$ - IS431) (Ito et al. 2001, 2004). Therefore, the SCCmec can be further classified into types, according to the combination of the mec complex class and the recombinase allotype (Table II), SCCmec type I presents mec complex class B and $c c r 1$; type II, mec complex class A and $c c r 2$; type III, mec complex class A and ccr3; type IV, mec complex B and $c c r 2$; and type $\mathrm{V}$, mec complex $\mathrm{C} 2$ and $c c r 5$. Recently, two possible additional SCCmec types have been identified among Australian

TABLE I

Staphylococcus aureus genes analyzed in the multilocus sequence typing technique (Enright et al. 2000)

\begin{tabular}{lc}
\hline Enzyme & Gene \\
\hline Carbamate kinase & $\operatorname{arcC}$ \\
Shikimate dehydrogenase & $\operatorname{aroE}$ \\
Glycerol kinase & $g l p F$ \\
Guanylate kinase & gmk \\
Phosphate acetyltransferase & pta \\
Triosephosphato isomerase & $t p i$ \\
Acetyl coenzyme A acetyltransferase & $y q i L$ \\
\hline
\end{tabular}

community-acquired MRSA (O'Brien at al. 2004).

The association of MLST and SCCmec typing supported a new nomenclature proposal for the MRSA epidemic clones. The lineages were classified according to the ST, resistance phenotype (MSSA, MRSA, VISA or VRSA) and SCCmec type. For example, the IC would be known as ST247-MRSA-I. The nomenclature for the major MRSA epidemic clones is shown in Table III. It is hoped that this nomenclature will replace the existing arbitrary designations providing a systematic classification of S. aureus clones (Enright et al. 2002).

TABLE III

Nomenclature of major methicillin-resistant Staphylococcus aureus epidemic clones (Enright et al. 2002)

\begin{tabular}{lrll}
\hline Epidemic clone & \multicolumn{1}{c}{ ST } & SCCmec & Nomenclature \\
\hline Brazilian & 239 & IIIA & ST239-MRSA-IIIA \\
Hungarian & 239 & IIIB & ST239-MRSA-IIIB \\
Iberian & 247 & I & ST246-MRSA-I \\
New York/Japan & 5 & II & ST5-MRSA-II \\
Pediatric & 5 & IV & ST5-MRSA-IV \\
\hline
\end{tabular}

ST: sequence type; SCCmec: staphylococcal cassette chromosome mec

\section{Studying $S$. aureus clonal complexes: establishing evolutive relationships among isolates}

In 2002, Enright et al. analyzed an international collection of hospital and community-acquired $S$. aureus isolates by MLST and SCCmec typing. The analysis revealed new information about clonal groups of S. aureus. Several clonal complexes (CC), composed by $S$. aureus isolates with the same ST or related STs (presenting at least five loci in common), were identified. Five major CCs included MRSA isolates: CC8, CC5, CC30, CC45, CC22. Interestingly, the comparison of the nucleotide sequences of MRSA and MSSA isolates included in CC8 allowed the establishment of a common MSSA ancestor. Different MRSA isolates would have originated from this MSSA ancestor by distinct events of mec cassette acquisition. These observations, in addition to other studies involving MLST, met Musser and Kapur's (1992) ideas about the horizontal transmission of mecA.

TABLE II

Characteristics of different types of staphylococcal cassette chromosome mec (SCCmec)

\begin{tabular}{|c|c|c|c|c|c|c|c|c|c|c|}
\hline \multirow[t]{2}{*}{ Type } & \multirow[t]{2}{*}{$\begin{array}{l}\text { Size } \\
(\mathrm{Kb})\end{array}$} & \multirow[t]{2}{*}{$\begin{array}{l}\text { Recombinase } \\
\text { complex }\end{array}$} & \multirow[t]{2}{*}{$\begin{array}{c}\text { mec } \\
\text { complex }\end{array}$} & \multicolumn{3}{|c|}{$\begin{array}{l}\text { Presence of additional } \\
\text { genetic elements }\end{array}$} & \multicolumn{3}{|c|}{ Strain of original description } & \multirow[t]{2}{*}{ Reference } \\
\hline & & & & IS431 & $\operatorname{Tn} 554$ & Other $^{a}$ & Strain name & Country & Year of isolation & \\
\hline I & 34 & ccrl & Class B & Yes & No & No & NCTC10442 & England & 1961 & Ito et al. 2001 \\
\hline II & 53 & $c c r 2$ & Class A & Yes & Yes & No & N315 & Japan & 1982 & \\
\hline III & 67 & $\operatorname{ccr} 3$ & Class A & Yes & Yes & Yes & $85 / 2082$ & New Zealand & 1985 & \\
\hline IV & $21-25$ & $\operatorname{ccr} 2$ & Class B & No & No & No & CA05 e 8/6-3P & USA & NR & Ma et al. 2002 \\
\hline V & 27 & $\operatorname{ccr} 5$ & Class C2 & Yes & No & No & WIS & Australia & NR & Ito et al. 2004 \\
\hline
\end{tabular}

$a$ : genes encoding resistance to non- $\beta$-lactam drugs; NR: not reported. 
Studies applying PFGE for MSSA typing have shown a large diversity of electrophoretic profiles among these isolates (Enright et al. 2000, Netto dos Santos et al. 2001). MLST of MSSA shows overlapping results: isolates presenting related PFGE profiles usually share the same ST or related STs ( Enright et al. 2002, Vivoni et al. 2004).

In 2001, Crisóstomo et al. analyzed a MSSA collection from the 1960s, obtained in Denmark previously to the first MRSA isolation. The study allowed the identification of probable MSSA ancestors of the Archaic, Pediatric and NY/Japan MRSA clones (Crisóstomo et al. 2001). However, studies involving more recent MSSA isolates (Mahmood et al. 2002, Enright et al. 2002, Vivoni et al. 2004) were not able to delineate associations between specific clones or CCs and the community or hospital origin of the isolates. They were able to show the predominance of some CCs though, suggesting that some lineages might present a better pathogenic or adaptive potential. Among isolates from the United Kingdom obtained between 1997 and 1998, the CC 30 is predominant, followed by CCs 25, 8 and 1 (Enright et al. 2000, 2002, Mahmood et al. 2002) In Brazil, isolates belonging to $\mathrm{CC} 1, \mathrm{CC} 30$ and CC 5 are prevalent (Vivoni et al. 2004).

\section{Conclusions}

A better understanding of the epidemiology of $S$. aureus contributes to the control, prevention and treatment of healthcare-associated and community-acquired infections. Molecular techniques are important tools in outbreak investigations and in global epidemiology studies, not only for S. aureus, but also for many other pathogens. However, the application of the appropriated technique is critical for the success of the study and production of accurate results.

Several studies cited in this review reinforce the idea that the horizontal transfer of the mecA gene to certain MSSA isolates originated MRSA lineages to become pandemic clones. However, studies involving isolates from several countries are necessary to establish the existence of disseminated $S$. aureus.

\section{REFERENCES}

Aires DS, de Lencastre H, Santos SI, Kikuchi K, Totsuka K, Tomasz A 2000. Similarity of antibiotic resistance patterns and molecular typing properties of methicillin-resistant Staphylococcus aureus isolates widely spread in hospitals in New York City and in a hospital in Tokyo, Japan. Microb Drug Resist 6: 253-258.

Aires DS, Miragaia M, Sanches IS, Avila S, Adamson I, Casagrande ST, Brandileone MC, Palacio R, Dell'Acqua L, Hortal M, Camou T, Rossi A, Velazquez-Meza ME, Echaniz-Aviles G, Solorzano-Santos F, Heitmann I, de Lencastre H 2001. Three-year assessment of methicillinresistant Staphylococcus aureus clones in Latin America from 1996 to 1998. J Clin Microbiol 39: 2197-2205.

Boerlin P 1997. Applications of multilocus enzyme electrophoresis in medical microbiology. J Microbiol Methods 28: 221-231.

Chambers HF 1997. Methicillin resistance in staphylococci: molecular and biochemical basis and clinical implications.
Clin Microbiol Rev 10: 781-791.

Corso A, Santos SI, Aires DS, Rossi A, de Lencastre H 1998. Spread of a methicillin-resistant and multiresistant epidemic clone of Staphylococcus aureus in Argentina. Microb Drug Resist 4: 277-288.

Crisóstomo MI, Westh H, Tomasz A, Chung M, Oliveira DC, de Lencastre H 2001. The evolution of methicillin resistance in Staphylococcus aureus: similarity of genetic backgrounds in historically early methicillin-susceptible and resistant isolates and contemporary epidemic clones. Proc Natl Acad Sci USA 98: 9865-9870.

de Sousa MA, Sanches IS, Ferro ML, Vaz MJ, Saraiva Z, Tendeiro T, Serra J, de Lencastre H 1998. Intercontinental spread of a multidrug-resistant methicillin-resistant Staphylococcus aureus clone. J Clin Microbiol 36: 2590-2596.

Del Vecchio VG, Petroziello JM, Gress MJ, McCleskey FK, Melcher GP, Crouch HK, Lupski JR 1995. Molecular genotyping of methicillin-resistant Staphylococcus aureus via fluorophore-enhanced repetitive-sequence PCR. J Clin Microbiol 33: 2141-2144.

Deplano A, Witte W, van Leeuwen WJ, Brun Y, Struelens MJ 2000. Clonal dissemination of epidemic methicillin-resistant Staphylococcus aureus in Belgium and neighboring countries. Clin Microbiol Infect 6: 239-245.

Diekema DJ, Pfaller MA, Schmitz FJ, Smayevsky J, Bell J, Jones RN, Beach M 2001. Survey of infections due to Staphylococcus species: frequency of occurrence and antimicrobial susceptibility of isolates collected in the United States, Canada, Latin America, Europe, and the Western Pacific region for the SENTRY Antimicrobial Surveillance Program, 1997-1999. Clin Infect Dis 32 (Suppl. 2): S114-S132.

Dominguez MA, de Lencastre H, Linares J, Tomasz A 1994. Spread and maintenance of a dominant methicillin-resistant Staphylococcus aureus (MRSA) clone during an outbreak of MRSA disease in a Spanish hospital. J Clin Microbiol 32: 2081-2087.

Enright MC, Day NP, Davies CE, Peacock SJ, Spratt BG 2000. Multilocus sequence typing for characterization of methicillin-resistant and methicillin-susceptible clones of Staphylococcus aureus. J Clin Microbiol 38: 1008-1015.

Enright MC, Robinson DA, Randle G, Feil EJ, Grundmann H, Spratt BG 2002. The evolutionary history of methicillinresistant Staphylococcus aureus (MRSA). Proc Natl Acad Sci USA 99: 7687-7692.

Ferrari L, Altamura M, De Luca M, Ceruti T 2002. MEN 10700, a new penem antibiotic: in vitro antibacterial activity on clinical isolates. Chemotherapy 48: 15-20.

Gomes AR, Sanches IS, Aires DS, Castañeda E, de Lencastre H 2001. Molecular epidemiology of methicillin-resistant Staphylococcus aureus in Colombian hospitals: dominance of a single unique multidrug-resistant clone. Microb Drug Resist 7: 23-32.

Grundmann H, Hori S, Enright MC, Webster C, Tami A, Feil EJ, Pitt T 2002. Determining the genetic structure of the natural population of Staphylococcus aureus: a comparison of multilocus sequence typing with pulsed-field gel electrophoresis, randomly amplified polymorphic DNA analysis, and phage typing. J Clin Microbiol 40: 4544-4546.

Hilton M, Chen JM, Barry C, Vearncombe M, Simor A 2002. 
Deoxyribonucleic acid fingerprinting in an outbreak of Staphylococcus aureus intracranial infection after neurotologic surgery. Otol Neurotol 23: 550-554.

Ito T, Katayama Y, Asada K, Mori N, Tsutsumimoto K, Tiensasitorn C, Hiramatsu K 2001. Structural comparison of three types of staphylococcal cassette chromosome mec integrated in the chromosome in methicillin-resistant Staphylococcus aureus. Antimicrob Agents Chemother 45: 1323-1336.

Ito T, Ma XX, Takeuchi F, Okuma K, Yuzawa H, Hiramatsu K 2004. Novel type V staphylococcal cassette chromosome mec driven by a novel cassette chromosome recombinase, ccrC. Antimicrob Agents Chemother 48: 2637-2651.

Jevons MP 1961. “Celbenin”-resistant staphylococci. Br Med J 1: 124-125.

Katayama Y, Ito T, Hiramatsu K 2000. A new class of genetic element, staphylococcus cassette chromosome mec, encodes methicillin resistance in Staphylococcus aureus. Antimicrob Agents Chemother 44: 1549-1555.

Kreiswirth B, Kornblum J, Arbeit RD, Eisner W, Maslow JN, McGeer A, Low DE, Novick RP 1993. Evidence for a clonal origin of methicillin resistance in Staphylococcus aureus. Science 259: 227-230.

Leski T, Oliveira D, Trzcinski K, Sanches IS, de Sousa MA, Hryniewicz W, de Lencastre H 1998. Clonal distribution of methicillin-resistant Staphylococcus aureus in Poland. J Clin Microbiol 36: 3532-3539.

Lim TT, Coombs GW, Grubb WB 2002. Genetic organization of mecA and mecA-regulatory genes in epidemic methicillin-resistant Staphylococcus aureus from Australia and England. J Antimicrob Chemother 50: 819-824.

Ma XX, Ito T, Tiensasitorn C, Jamklang M, Chongtrakool P, Boyle-Vavra S, Daum RS, Hiramatsu K 2004. Novel type of staphylococcal cassette chromosome mec identified in community-acquired methicillin-resistant Staphylococcus aureus strains. Antimicrob Agents Chemother 46: 11471152.

Mahmood A, Karamat KA, Butt T 2002. Neonatal sepsis: high antibiotic resistance of the bacterial pathogens in a neonatal intensive care unit in Karachi. J Pak Med Assoc 52: 348350 .

Mato R, Santos S, I, Venditti M, Platt DJ, Brown A, Chung M, de Lencastre H 1998. Spread of the multiresistant Iberian clone of methicillin-resistant Staphylococcus aureus (MRSA) to Italy and Scotland. Microb Drug Resist 4: 107112.

Melter O, Aires DS, Urbaskova P, Jakubu V, Zemlickova H, de Lencastre H 2003. Update on the major clonal types of methicillin-resistant Staphylococcus aureus in the Czech Republic. J Clin Microbiol 41: 4998-5005.

Montesinos I, Salido E, Delgado T, Cuervo M, Sierra A 2002. Epidemiologic genotyping of methicillin-resistant Staphylococcus aureus by pulsed-field gel electrophoresis at a university hospital and comparison with antibiotyping and protein A and coagulase gene polymorphisms. J Clin Microbiol 40: 2119-2125.

Musser JM, Kapur V 1992. Clonal analysis of methicillin-resistant Staphylococcus aureus strains from intercontinental sources: association of the mec gene with divergent phy- logenetic lineages implies dissemination by horizontal transfer and recombination. J Clin Microbiol 30: 2058-2063.

Netto dos Santos KR, de Souza FL, Teixeira LM, Gontijo Filho PP 2001. Typing of Staphylococcus aureus from surgical site infections: comparison of pulsed-field gel electrophoresis (PFGE) and PCR technique using repetitive extragenic palindromic (rep) and Tn916-Shine-Dalgarno (TnSD) target sequences. Int J Med Microbiol 291: 231-236.

NNIS System 2004. National Nosocomial Infections Surveillance (NNIS) System Report, data summary from January 1992 through June 2004. Am J Infect Control 32: 470-485.

Nunes de Melo MC, Silva-Carvalho MC, Ferreira RL, Rocchetto LC, Souza RR, Sobbi CN, Rosenbaum CA, Solari CA, Ferreira-Carvalho BT, Figueiredo AMS 2004. Detection and molecular characterization of gentamicin-susceptible, methicillin-resistant Staphylococcus aureus (MRSA) clone in Rio de Janeiro that resembles the New York-Japanese clone. J Hosp Infec 58: 276-285.

O'Brian FG, Lim TT, Chong FN, Coombs GW, Enright MC, Robinson DA, Monk A, Said-Salim B, Kreiswirth BN, Grubb WB 2004. Diversity among community isolates of methicillin-resistant Staphylococcus aureus in Australia. $J$ Clin Microbiol 42: 3185-3190.

Olive DM, Bean P 1999. Principles and applications of methods for DNA-based typing of microbial organisms. J Clin Microbiol 37: 1661-1669.

Oliveira DC, Tomasz A, de Lencastre H 2002. Secrets of success of a human pathogen: molecular evolution of pandemic clones of meticillin-resistant Staphylococcus aureus. Lancet Infect Dis 2: 180-189.

Paradisi F, Corti G, Messeri D 2001. Antistaphylococcal (MSSA, MRSA, MSSE, MRSE) antibiotics. Med Clin North Am 85: $1-17$.

Roberts RB, Chung M, de Lencastre H, Hargrave J, Tomasz A, Nicolau DP, John Jr JF, Korzeniowski O 2000. Distribution of methicillin-resistant Staphylococcus aureus clones among health care facilities in Connecticut, New Jersey, and Pennsylvania. Microb Drug Resist 6: 245-251.

Roberts RB, de Lencastre A, Eisner W, Severina EP, Shopsin B, Kreiswirth BN, Tomasz A 1998a. Molecular epidemiology of methicillin-resistant Staphylococcus aureus in 12 New York hospitals. MRSA Collaborative Study Group. $J$ Infect Dis 178: 164-171.

Roberts RB, Tennenberg AM, Eisner W, Hargrave J, Drusin LM, Yurt R, Kreiswirth BN 1998b. Outbreak in a New York City teaching hospital burn center caused by the Iberian epidemic clone of MRSA. Microb Drug Resist 4: 175-183.

Sa-Leao R, Santos SI, Dias D, Peres I, Barros RM, de Lencastre H 1999. Detection of an archaic clone of Staphylococcus aureus with low-level resistance to methicillin in a pediatric hospital in Portugal and in international samples: relics of a formerly widely disseminated strain? J Clin Microbiol 37: 1913-1920.

Sader HS, Pignatari AC, Hollis RJ, Jones RN 1994. Evaluation of interhospital spread of methicillin-resistant Staphylococcus aureus in São Paulo, Brazil, using pulsed-field gel electrophoresis of chromosomal DNA. Infect Control Hosp Epidemiol 15: 320-323.

Sanches IS, Saraiva ZC, Tendeiro TC, Serra JM, Dias DC, de 
Lencastre H 1998. Extensive intra-hospital spread of a methicillin-resistant staphylococcal clone. Int J Infect Dis 3: 26-31.

Saulnier P, Bourneix C, Prevost G, Andremont A 1993. Random amplified polymorphic DNA assay is less discriminant than pulsed-field gel electrophoresis for typing strains of methicillin-resistant Staphylococcus aureus. J Clin Microbiol 31: 982-985.

Shopsin B, Kreiswirth BN 2001. Molecular epidemiology of methicillin-resistant Staphylococcus aureus. Emerg Infect Dis 7: 323-326.

Teixeira LA, Resende CA, Ormonde LR, Rosenbaum R, Figueiredo AM, de Lencastre H, Tomasz A 1995. Geographic spread of epedemic multiresistant Staphylococcus aureus clone in Brazil. J Clin Microbiol 33: 2400-2404.

Tenover FC, Arbeit RD, Goering RV, Mickelsen PA, Murray BE, Persing DH, Swaminathan B 1995. Interpreting chromosomal DNA restriction patterns produced by pulsed-field gel electrophoresis: criteria for bacterial strain typing. J Clin Microbiol 33: 2233-2239. van Belkum A, van Leeuwen W, Kaufmann ME, Cookson B, Forey F, Etienne J, Goering R, Tenover F, Steward C, O'Brien F, Grubb W, Tassios P, Legakis N, Morvan A, El Solh N, De Ryck R, Struelens M, Salmenlinna S, VuopioVarkila J, Kooistra M, Talens A, Witte W, Verbrugh H 1998. Assessment of resolution and intercenter reproducibility of results of genotyping Staphylococcus aureus by pulsed-field gel electrophoresis of SmaI macrorestriction fragments: a multicenter study. J Clin Microbiol 36: 1653-1659.

Vivoni AM, Diep BA, Gouveia AC, Riley LW, Sensabaugh GF, Moreira BM 2004. Molecular characterization of Staphylococcus aureus isolates at a public university hospital, Brazil. 44th Interscience Conference on Antimicrobial Agents and Chemotherapy Abstracts, Washington DC: p. 308.

Wei HL, Chiou CS 2002. Molecular subtyping of Staphylococcus aureus from an outbreak associated with a food handler. Epidemiol Infect 128: 15-20.

Witte W, Cuny C, Braulke C, Heuck D 1994. Clonal dissemination of two MRSA strains in Germany. Epidemiol Infect 113: 67-73. 